\title{
Chinese High School Students' Mathematics-Related Beliefs and Their Perceived Mathematics Achievement: A Focus on Teachers' Praise
}

\author{
Guangming Wang ${ }^{{ }^{*}}$, Sheng Zhang ${ }^{1}$, Jinfa Cai ${ }^{2}$ \\ ${ }^{1}$ College of Teacher Education, Tianjin Normal University, CHINA \\ ${ }^{2}$ Department of Mathematical Sciences, University of Delaware, USA
}

Received 6 June 2018 - Revised 31 October 2018 - Accepted 13 December 2018

\begin{abstract}
This study examined the relationships between mathematics teachers' praise and students' mathematics-related beliefs and their perceived mathematics achievement rank in their respective classes. This study provided reliability and validity information about an instrument to assess high school students' mathematics beliefs. Students' mathematics-related beliefs are positively related to teachers' praise, as well as students' perceptions of their own achievement rank in their respective classes. While it was found that the proportion of students who reported that their teachers praised them was relatively low (about 28\%), the more praise teachers provide, the more desirable mathematics-related beliefs students have. In addition, the more praise teachers provide, the higher students perceived achievement. The findings of this study suggest that teachers' praise may foster more desirable mathematics-related beliefs and achievement.
\end{abstract}

Keywords: China, mathematics, students' mathematics-related beliefs, teacher praise

\section{INTRODUCTION}

Students' beliefs related to mathematics have long been an important topic of study in mathematics education, both because of their relationship to affect and motivation (McLeod, 1992; Middleton, Jansen, \& Goldin, 2017) and because of their potential influence on students' mathematical thinking and activity (Schoenfeld, 1989, 1992). Indeed, the teaching and learning of mathematics necessarily involves affective and noncognitive considerations including beliefs, emotions, values, and attitudes (Cai et al., 2017; Clarkson, Bishop, \& Seah, 2010; Leder, 1993; Moyer, Robinson, \& Cai, 2018; Pepin \& Roesken-Winter, 2015). Op't Eynde, De Corte, and Verschaffel (2002) developed a comprehensive categorization of mathematics beliefs: beliefs about mathematics education, beliefs about the self, and beliefs about social context. Each of these categories of mathematics-related beliefs is potentially related to students' mathematical behavior.

Moreover, mathematics-related beliefs have been studied as predictors of students' mathematical achievement (House, 2009; Lay, $\mathrm{Ng}$, \& Chong, 2015). Given the potential ways in which mathematics-related beliefs both influence and are influenced by factors, such as mathematics achievement and interactions with parents and teachers, it is hardly surprising that students' mathematics-related beliefs are increasingly emerging as an important topic in the international mathematics education research community. Studies have shown that teachers' behaviors have an effect on educational aspirations, cognitive ability, mathematics achievement, mathematics learning, motivational beliefs about mathematics, mathematical self-efficacy, and so forth (e.g., Levpušček \& Zupančič, 2009; Phillipson, 2010; Zijlstra, Wubbels, Brekelmans \& Koomen, 2013). However, there has not been a systematic body of research focusing on the influence of factors such as teachers on students' mathematics-related beliefs.

Students in East Asian countries and regions have excelled in large-scale international academic assessments such as TIMSS and PISA. Studies have shown that this has a certain relationship with the performance of teachers

(C) 2019 by the authors; licensee Modestum Ltd., UK. This article is an open access article distributed under the terms and conditions of the Creative Commons Attribution License (http://creativecommons.org/licenses/by/4.0/). 《bd690310@163.com 《 bd6903100@163.com 《jcai@udel.edu (*Correspondence) 


\section{Contribution of this paper to the literature}

- Provides a valid and reliable instrument to assess Chinese students' mathematics-related beliefs.

- Students' mathematics-related beliefs are positively related to teachers' praise, as well as students' perceptions of their own achievement rank in their respective classes.

- While it was found that the proportion of students who reported that their teachers praised them was relatively low (about 28\%), the more praise teachers provide, the more desirable mathematics-related beliefs students have.

- $\quad$ The more praise teachers provide, the higher students perceived achievement.

- The findings of this study suggest that teachers' praise may foster more desirable mathematics-related beliefs and achievement.

(Phillipson \& Phillipson, 2007). China is a typical representative of the Confucian Heritage Culture (CHC) countries (Fan, Wong, Cai, \& Li, 2004) which exhibit these culturally situated factors. The research reported here was designed to investigate the current status of mathematics-related beliefs among Chinese senior high school students, to analyze the influence of Chinese teachers on the beliefs of high school students in mathematics, and to provide a reference point for education in other countries and regions.

In particular, this study is designed to investigate the following two research questions:

1) How are teachers' appraisals related to students' mathematics-related beliefs and their perceived mathematics achievement?

2) How are students' mathematics-related beliefs related to their perceived achievement?

\section{THEORETICAL BASES}

\section{Teacher Interpersonal Behavior}

Early research showed that when students feel that their teachers value, care for, and support them, they are more likely to have higher motivation for academic achievement (Goodnow, 1993; Wentzel, 1997). Patrick, Ryan, and Kaplan (2007) pointed out that such support includes the teacher caring about students' learning, trying to help them learn, and encouraging them to do their best. In addition, some studies have shown that teacher care (teacher support) has a significant effect on students' academic performance after controlling for family factors (Marchant, Paulson \& Rothlisberg, 2001). Indeed, Levpušček and Zupančič (2009) found that the support and encouragement of mathematics teachers had an even greater impact on students' mathematics achievement than parental education, although they noted that "the combined effect of both student-rated family and classroom context on eighth graders' math performance is stronger than the effect of either context alone" (p. 563).

Based on the existing research, Lapointe, Legault, and Batiste (2005) further explored the influence of teacher interpersonal behavior on students' mathematics learning motivation and found that mathematics teachers' interpersonal relationship behaviors have a significant effect on both regular students and students identified as talented. Zijlstra, Wubbels, Brekelmans, and Koomen (2013) investigated the relationship between 6-9 year-old students' perceptions of teacher interpersonal behavior and achievement in mathematics and found that students' views on mathematics teachers' control and connection were important predictors of student achievement in mathematics.

In summary, the existing studies mostly examine the effects of the behavior of teachers on overall mathematics academic achievement and mathematics learning motivation but have not paid detailed attention to the influence of mathematics teacher behavior on students' mathematics-related beliefs (although see the discussion of Levpušček \& Zupančič, 2009, about the mediating role of self-efficacy between parental and teacher influences and mathematics achievement). The present study focuses in particular on the encouragement of mathematics teachers' evaluative speech, specifically the influence of mathematics teachers' praise on students' mathematics-related beliefs. Based on the existing research, it is assumed that positive recognition by the mathematics teacher has a positive influence on students' mathematics-related beliefs, and that its influence may be greater than parental education expectations.

\section{Mathematics Achievement and Self-Efficacy}

A large number of studies have shown that there is a significant correlation between student mathematicsrelated beliefs and student mathematics achievement (e.g., House, 2009; Lay, Ng, \& Chong, 2015). These studies typically use students' mathematics achievement as a dependent variable and some particular student mathematics-related beliefs, including beliefs about mathematics self-efficacy, as predictors. For example, Skaalvik 
Table 1. Participants' Background Information

\begin{tabular}{|c|c|c|}
\hline & Number of participants & $\%$ \\
\hline \multicolumn{3}{|l|}{ Gender } \\
\hline Male & 250 & 50.4 \\
\hline Female & 246 & 49.6 \\
\hline \multicolumn{3}{|l|}{ Grade } \\
\hline 10 & 265 & 53.4 \\
\hline 11 & 136 & 27.4 \\
\hline 12 & 95 & 19.2 \\
\hline
\end{tabular}

and Skaalvik (2011) explored the relationship between mathematics self-concept and self-efficacy and mathematics achievement. They found that students' self-efficacy was a strong predictor of achievement even beyond prior achievement. Pantziara (2016) noted, however, that few of these studies "provide causal ordering between the two constructs" (p. 8) of mathematics self-efficacy and mathematics achievement. Nevertheless, House (2009) concluded after a series of studies that students with better mathematics performance tend to have more positive mathematicsrelated beliefs, and those with poor mathematics performance have more negative mathematics-related beliefs. In other words, students' academic achievement in mathematics may have a positive effect on students' mathematicsrelated beliefs and vice versa.

In this study, the students' perception of their relative mathematics achievement ranking in their class is used as the measure of student achievement, and we assume that the students' perceived class mathematics achievement ranking may have a positive influence on their mathematics-related beliefs (and vice versa). In a study of mathematics students in Finland, Hannula, Bofah, Tuohilampi, and Metsamuuronen (2014) found that mathematics achievement and self-efficacy had a reciprocal relation, where the dominant effect was from achievement to selfefficacy. They also found a weaker unidirectional effect from achievement to emotion. Cai and Merlino (2011) also found that students' success in mathematical achievement was linked to positive mathematical dispositions. Students who succeeded in the process of learning mathematics through concerted effort in overcoming challenges gained a sense of satisfaction that bolstered their motivation to continue challenging themselves in mathematics. Cai and Merlino (2011) posited that this could produce a positive disposition-performance cycle.

\section{METHOD}

\section{Participants}

A survey was administered nationwide using a combination of online sampling and regional cluster sampling. The survey began with regional cluster sampling, and this was followed by an online sampling to ensure a high response rate. In total, 496 valid questionnaires were collected. The participants came from the following parts of China: Central China, North China, East China, South China, Northwest China, Northeast China and Southwest China. The background information of the participants is shown in Table 1.

\section{Instrument}

The survey instrument was adapted from a questionnaire originally developed by Op't Eynde and De Corte (2003). Because PISA and TIMSS are international assessment projects that include items related to mathematics beliefs, we also drew on those assessments in the development of the questionnaire. However, although we included items drawn from PISA and TIMSS, the instrument developed by Op't Eynde and De Corte had useful theoretical properties with respect to beliefs subscales. Thus, we made use of this theoretical structure by adopting the first three of the four subscale categories established by Op't Eynde and De Corte. We focused our fourth subscale on mathematics anxiety, using items from TIMSS.

The survey instrument underwent three stages of revision and refinement before being used in this study. In each stage, a group of mathematics education researchers have served as expert to ensure the content validity. In this section, we discuss the process of developing the Chinese version of the instrument.

\section{The preliminary edition and its piloting}

The Students' Mathematics-Related Beliefs Questionnaire (SMRBQ) compiled by Op't Eynde and De Corte (2003) was revised for use with Chinese high school students. We called the revised instrument the High School Student Mathematics Belief Questionnaire. The English version of the SMRBQ was translated into Chinese and then translated back into English by graduate students with good English language skills. We revised the Chinese version by comparing the result with the original English version. Taking into account applicability under the 
background of Chinese mathematics education and the accuracy of the terms in the questionnaire, combined with the characteristics of mathematics studying of Chinese high school students, and drawing on the PISA-2012 background questionnaires and the TIMSS-2015 background questionnaires on student mathematics-related belief items, we added or deleted some items, eventually forming the preliminary draft of a mathematics-related belief questionnaire with 52 items for high school students. The preliminary draft of the questionnaire retained three of the four subquestionnaires included in the original questionnaire. These were 1) beliefs about the role and the functioning of their own teacher, 2) beliefs about the significance of and competence in mathematics, and 3) mathematics as a social activity (Op't Eynde \& De Corte, 2003). The preliminary draft also included items, primarily from TIMSS-2015, comprising a fourth subquestionnaire that focused on mathematics anxiety. All 52 items were randomly arranged. Nine of the items were scored in reverse.

The preliminary edition of the questionnaire was piloted with 190 students in two high schools of Tianjin City. In total, 182 responses were collected, and 174 valid responses were examined with item analyses. The participants in the pilot were 80 boys and 94 girls; 61 students were in 10th grade and 113 students were in 11th grade. The pilot data were used to examine the clarity of the language used in the items. The questionnaire was revised based on the pilot data. In particular, based on the analysis of results from piloting, the feedback from the subjects, and the suggestions of the in-service secondary mathematics teachers, the following changes were made: two items were deleted because they did not achieve significant differences between the high and low groups; one item was deleted because the Critical Ratio was low; and regarding the item, "I need mathematics to help me learn other subjects," we added examples such as "Physics, Geography, and so forth" to the text of the item in order to make the questionnaire easier for high school students to understand. Thus, the second edition of the questionnaire contained 49 items and had the same structure as the initial draft questionnaire.

\section{The second edition and its validation}

The second edition of the questionnaire was administered in 13 secondary schools from nine cities in China. In total, 960 questionnaires were distributed, 936 were returned, and 902 were valid. Through item analysis and exploratory factor analysis, we deleted those items which did not meet the psychometric criteria (with low loading). The participants in this second round were 460 boys and 448 girls; 402 were in 10th grade, 356 were in 11th grade, and 150 were in 12 th grade.

Based on the total scores of students' mathematics-related beliefs, the top $27 \%$ were considered the high score group and the bottom $27 \%$ the low score group. The independent samples $t$ test was conducted for the scores on each item for the high and low score groups, and a correlation analysis was also implemented between all the items and the total scores of each subquestionnaire. The deletion criteria for the correlation coefficient between all items and the subquestionnaire was set at 0.40 . One item with insignificant $t$ value and 3 items with correlation coefficients less than 0.40 were deleted, and 45 items were retained. The correlation coefficients between the scores from the 45 items and the total score of the subquestionnaires was distributed between 0.45 and 0.85 (all $p<0.001$ ).

An exploratory factor analysis was conducted on the remaining 45 items. The results indicated that the KMO values of each subquestionnaire in the exploratory factor analysis ranged from 0.82 to 0.95, and Bartlett's sphere test reached a significant level $(p<0.001)$. The results revealed that each subquestionnaire was suitable for the factor analysis.

According to the research objectives and theoretical conceptions, after the first factor analysis of each subscale, we first deleted the items with the highest load on the other extracted factors and then conducted factor analysis again, so that the item-by-item deletion was performed successively for a series of factor analyses until the final extracted factors were in line with the theoretical conceptions. In the end, the entire questionnaire retained 40 items, and the load of factors for each item on the subscales ranged from 0.57 to 0.89 . The explained variation ranged from $54.83 \%$ to $61.49 \%$.

The Cronbach's a coefficients of the subscales and the a coefficients of the 40 items were examined. The results showed that the a coefficient after the two items in the subscale of Beliefs about the significance of and competence in mathematics had been deleted was 0.934 , and the a coefficient after an item in the subscale of Mathematics as a social activity was deleted was 0.882 , both of which were greater than the Cronbach's a coefficients of the respective subscale. The a coefficient of the Beliefs about the role and the functioning of their own teacher is equal to the Cronbach's a coefficient of the subscale, which indicates that after the deletion of the item, the reliability of the subscale was not changed. Finally, 36 items were retained.

The scores of students' mathematics-related beliefs were ranked. The top $27 \%$ were considered the high score group and the bottom $27 \%$ the low score group. The scores of high and low groups on each item were tested by independent samples $t$ test. The results showed that the high score group's scores on the 36 items were significantly different from the low score group's scores, and all items had good discrimination. 
Table 2. Goodness of Fit of Four-Factor Model for the High School Students Mathematics Belief Questionnaire

\begin{tabular}{cccccccc}
\hline$\chi^{2}$ & $\mathrm{df}$ & NC & RMSEA & GFI & AGFI & PGFI & CN \\
\hline $1200.66^{\star \star \star}$ & 629 & 1.91 & 0.05 & 0.82 & 0.80 & 0.73 & 209 \\
\hline
\end{tabular}

Note: ${ }^{* \star *} p<.001$

Table 3. Correlation Coefficients of the High School Students Mathematics Belief Questionnaire, the IMBS Subscale of Timeconsuming Mathematics Problem Solving, and FSMAS

\begin{tabular}{|c|c|c|c|c|c|c|c|}
\hline 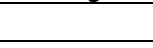 & Subscale 1 & Subscale 2 & Subscale 3 & Subscale 4 & Overall scale & IMBS & FSMAS \\
\hline Subscale 1 & 1 & & & & & & \\
\hline Subscale 2 & $0.58^{* * *}$ & 1 & & & & & \\
\hline Subscale 3 & $0.61^{* * *}$ & $0.53^{* * *}$ & 1 & & & & \\
\hline Subscale 4 & $0.36^{* * *}$ & $0.34^{* * *}$ & $0.31^{* * *}$ & 1 & & & \\
\hline Overall & $0.82^{\star * *}$ & $0.91^{\star \star *}$ & $0.81^{* * *}$ & $0.76^{\star * *}$ & 1 & & \\
\hline IMBS & $0.28^{\star * *}$ & $0.55^{\star \star *}$ & $0.33^{* * *}$ & $0.46^{\star * *}$ & $0.52^{\star \star \star}$ & 1 & \\
\hline FSMAS & $0.44^{* * *}$ & $0.40^{* * *}$ & $0.53^{* * *}$ & $0.11^{* \star *}$ & $0.49 * * *$ & $0.29 * * *$ & 1 \\
\hline
\end{tabular}

\section{The third edition and its reliability and validity}

The third edition of the questionnaire was administered to students from five secondary schools in four cities. These schools did not administer the two earlier versions of the questionnaire. There were 370 questionnaires distributed; 362 were returned, and 351 of those were valid. We reconfirmed the factors through confirmatory factor analysis and obtained the reliability and validity indices. The participants in this round were 179 boys and 167 girls, with 5 participants missing a gender record; 109 were in 10th grade, 137 were in 11th grade, and 105 were in 12 th grade.

The reliability analysis of the high school students' belief in mathematics questionnaire showed that the Cronbach's a coefficient of each scale was between 0.84 and 0.95 (see Table 4), the retest reliability was between 0.79 and 0.87 , which are reasonably high.

With respect to the construct validity, a maximum likelihood method was used to perform a confirmatory factor analysis on the officially tested sample $(n=351)$. The four subscales were used to constitute a four-factor model. We selected $\chi 2$, NC, RMSEA, GFI, AGFI, PGFI, and CN as evaluation indicators for the fit of the model. The results are shown in Table 2.

For the fit of the hypothesis model, $\chi^{2}=1200.66, d f=629, p<0.001$, and $\chi^{2}$ reached a significant level, which does not meet the standard. However, $\chi^{2}$ is susceptible to sample size and sample distribution, so this value is for reference only. $\mathrm{NC}(\chi 2 / d f)=1.91$, which is between 1.00 and 3.00, indicating that the model's fit is high. Both PGFI $=0.73>0.50$ and $\mathrm{CN}=209>200$ indicate that the four-factor model meets the fit criteria. Neither GFI nor AGFI reached the standard of 0.90, but Anderson and Gerbing (1984) advocated using 0.80 as the critical value for goodness of fit, so both GFI $=0.82$ and AGFI $=0.80$ are acceptable. RMSEA, as an indicator of noncentralized Chisquare indicators in the third category, which is not affected by sample distribution and sample size, is very suitable for estimating the power of statistical tests. The smaller the RMSEA value is, the better the fit of the model is. The RMSEA value of the four-factor model was 0.05 , which means a good fit. In summary, the four-factor model fit index reached the basic standard.

For the criterion validity, the subscale of time-consuming mathematics problem solving and the mathematical usefulness attitude scale (FSMAS) in the Indiana Mathematical Belief Scale (IMBS) (Fennema \& Sherman, 1976) were treated as criteria. There was a significant positive correlation between the scales (see Table 3 ). The correlation coefficients between the four subscales were between 0.31 and 0.61 . The correlation coefficients between the four subscales and the overall scale were between 0.76 and 0.91 . This shows that the four subscales are relatively independent and can make a greater contribution to the entire questionnaire. The overall questionnaire has good construct validity.

\section{Measures}

The revised High School Students Mathematics Belief Questionnaire was used to measure the levels of the students' mathematics-related beliefs. Four additional questions were included in the Questionnaire on High School Students' Belief in Mathematics to investigate mathematics teachers' praise, and mathematics achievement ranking in the class. Table 4 lists the questionnaire items used for these four topics. 
Table 4. Four Additional Items from the Questionnaire

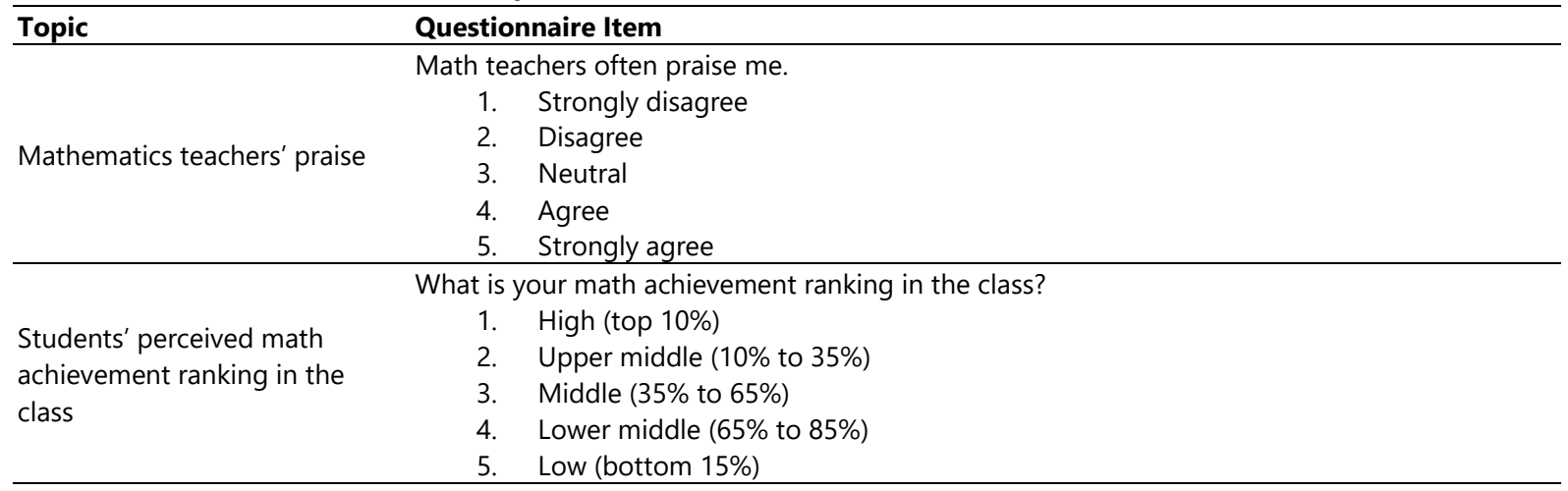

\section{RESULTS}

We present the results in three sections. The first section deals with relationships between students' mathematics-related beliefs and the measured factors regarding mathematics teachers' praise. The second section examines relationships between students' perceived mathematics achievement rankings in the class and mathematics teachers' praise. The third section deals with the relationship between students' perceived mathematics achievement rankings in the class and students' mathematics-related beliefs.

\section{Mathematics-Related Beliefs and Teacher Praises}

In order to examine the relationships between the mathematics-related beliefs scores (total and for each subscale) and teachers' praise, we conducted an ANOVA analysis for each factor and each belief score (total or subscale). Table 5 shows the results for teachers' praise and students' mathematics-related beliefs. As indicated in Table 5, only about $28 \%$ (139 out of 496 ) of the students agreed or strongly agreed that their teachers gave them praise. In contrast, over one third of the students disagreed or strongly disagreed that their teachers gave them praise. Overall, the higher the degree of teachers' praise, the more positive the students' mathematics-related beliefs were. For example, the mean overall mathematics-related beliefs score for those students who strongly agreed that their teachers praised them was 147 . However, the mean score for those students who strongly disagreed that their teachers praised them was 102. These findings for overall mathematics-related beliefs remained consistent across the first three subscales of mathematics-related beliefs. For the fourth subscale, the ANOVA analysis did not show a significant difference. 
EURASIA J Math Sci and Tech Ed

Table 5. Teachers' Praise and Students' Mathematics-Related Beliefs

\begin{tabular}{|c|c|c|c|c|c|c|}
\hline & Teachers' Praise & Mean & $S D$ & \# of Students & $\boldsymbol{F}$ & $\eta^{2}$ \\
\hline \multirow{5}{*}{$\begin{array}{l}\text { Mathematics-Related Beliefs } \\
\text { (total) }\end{array}$} & Strongly Disagree & 102.2910 & 24.24269 & 61 & \multirow{5}{*}{$51.008^{* * *}$} & \multirow{5}{*}{.294} \\
\hline & Disagree & 114.6824 & 17.19791 & 110 & & \\
\hline & Neutral & 127.1509 & 18.01370 & 186 & & \\
\hline & Agree & 134.7883 & 15.92462 & 94 & & \\
\hline & Strongly Agree & 147.0222 & 25.59163 & 45 & & \\
\hline \multirow{5}{*}{$\begin{array}{l}\text { Beliefs about the role and the } \\
\text { functioning of their own } \\
\text { teacher instruction }\end{array}$} & Strongly Disagree & 39.9180 & 11.97956 & 61 & \multirow{5}{*}{$45.216^{* \star *}$} & \multirow{5}{*}{.269} \\
\hline & Disagree & 45.1578 & 8.06569 & 110 & & \\
\hline & Neutral & 49.9856 & 8.05507 & 186 & & \\
\hline & Agree & 53.2522 & 6.70143 & 94 & & \\
\hline & Strongly Agree & 59.1556 & 9.37588 & 45 & & \\
\hline \multirow{5}{*}{$\begin{array}{l}\text { Beliefs about the significance } \\
\text { of and competence in } \\
\text { mathematics }\end{array}$} & Strongly Disagree & 27.8648 & 10.68291 & 61 & \multirow{5}{*}{$33.072^{\star \star *}$} & \multirow{5}{*}{.212} \\
\hline & Disagree & 31.6791 & 7.79893 & 110 & & \\
\hline & Neutral & 36.6707 & 7.85458 & 186 & & \\
\hline & Agree & 39.7275 & 7.84698 & 94 & & \\
\hline & Strongly Agree & 43.2667 & 11.43440 & 45 & & \\
\hline \multirow{5}{*}{$\begin{array}{l}\text { Mathematics as a social } \\
\text { activity }\end{array}$} & Strongly Disagree & 20.0984 & 7.11502 & 61 & \multirow{5}{*}{$29.369^{* \star *}$} & \multirow{5}{*}{.193} \\
\hline & Disagree & 23.0364 & 5.01544 & 110 & & \\
\hline & Neutral & 25.5538 & 4.52857 & 186 & & \\
\hline & Agree & 27.2447 & 4.35936 & 94 & & \\
\hline & Strongly Agree & 29.0889 & 6.60173 & 45 & & \\
\hline \multirow{5}{*}{ Mathematics anxiety } & Strongly Disagree & 14.4098 & 6.14377 & 61 & \multirow{5}{*}{0.459 n.s. } & \multirow{5}{*}{.004} \\
\hline & Disagree & 14.8091 & 4.04900 & 110 & & \\
\hline & Neutral & 14.9409 & 4.26700 & 186 & & \\
\hline & Agree & 14.5638 & 4.08659 & 94 & & \\
\hline & Strongly Agree & 15.5111 & 6.55959 & 45 & & \\
\hline
\end{tabular}

Note: ${ }^{* \star} p<.001$, n.s. $p>.05$

Table 6. Students' perceived class rank

\begin{tabular}{lcc}
\hline Class Rank & Number of participants & $\%$ \\
\hline High (top 10\%) & 41 & 8.3 \\
\hline Upper middle (10\%-35\%) & 119 & 24.0 \\
\hline Middle (35\% - 65\%) & 158 & 32.1 \\
\hline Lower middle (65\% -85\%) & 108 & 21.8 \\
\hline Low (bottom 15\%) & 69 & 13.9 \\
\hline
\end{tabular}

\section{Perceived Mathematics Achievement and Teacher Praise}

In addition to examining the relationships between the mathematics-related belief subscale scores and teacher praise, we also examined the relationships between the students' perceived mathematics achievement (reported as their perceived ranking in class) and teacher praise. Table 6 shows the distribution of students' perceived mathematics achievement rankings in the class. A High class rank indicates that the subject's mathematics grades were generally in the top $10 \%$ of the class, Upper Middle represents a ranking from $10 \%$ to $35 \%$, Middle means $35 \%$ to $65 \%$, Lower Middle means a ranking of $65 \%$ to $85 \%$, and Low indicates that the math grades are in the bottom $15 \%$.

Chi-square tests were conducted to probe the relationships between students' perceived mathematics achievement and teacher praise. As Table 7 shows, students' perceptions of their own class ranking were significantly associated with their reporting of receiving their teachers' praise. That is, there was a clear relationship between teacher praise and students' perceived achievement ranking in class. 
Table 7. Teachers' Praise and Students' Perceived Achievement

\begin{tabular}{llccccccc}
\hline & \multicolumn{7}{c}{ Mathematics teachers' praise } \\
\hline & $\begin{array}{l}\text { Strongly } \\
\text { Disagree }\end{array}$ & Disagree & Neutral & Agree & $\begin{array}{c}\text { Strongly } \\
\text { Agree }\end{array}$ & Total \\
\hline \multirow{3}{*}{$\begin{array}{l}\text { Students' Perceived } \\
\text { Ranking in Their Respective } \\
\text { Classes }\end{array}$} & 19 & 26 & 18 & 1 & 5 & 69 \\
\cline { 2 - 9 } & Low & 15 & 27 & 33 & 21 & 12 & 108 \\
\hline
\end{tabular}

Note : ${ }^{* \star} p<.001$

Table 8. Students' Perceived Achievement and Students' Math-Related Beliefs

\begin{tabular}{|c|c|c|c|c|c|c|}
\hline & Perceived Achievement & Mean & $S D$ & \# of Students & $\boldsymbol{F}$ & $\eta^{2}$ \\
\hline \multirow{5}{*}{$\begin{array}{l}\text { Mathematics-Related } \\
\text { Beliefs (total) }\end{array}$} & Low & 108.3862 & 21.94739 & 69 & \multirow{5}{*}{$29.507^{\star * *}$} & \multirow{5}{*}{0.194} \\
\hline & Lower Middle & 118.0581 & 22.48730 & 108 & & \\
\hline & Middle & 123.5675 & 20.06813 & 159 & & \\
\hline & Upper Middle & 134.9147 & 17.89734 & 119 & & \\
\hline & High & 142.9258 & 20.64717 & 41 & & \\
\hline \multirow{5}{*}{$\begin{array}{l}\text { Beliefs about the role } \\
\text { and the functioning of } \\
\text { their own teacher } \\
\text { instruction }\end{array}$} & Low & 45.1978 & 10.65033 & 69 & \multirow{5}{*}{$8.254^{* * *}$} & \multirow{5}{*}{0.063} \\
\hline & Lower Middle & 47.6970 & 10.49410 & 108 & & \\
\hline & Middle & 48.7280 & 9.66997 & 159 & & \\
\hline & Upper Middle & 51.4177 & 8.61173 & 119 & & \\
\hline & High & 54.4146 & 8.38742 & 41 & & \\
\hline \multirow{5}{*}{$\begin{array}{l}\text { Beliefs about the } \\
\text { significance of and } \\
\text { competence in } \\
\text { mathematics }\end{array}$} & Low & 27.2319 & 8.38266 & 69 & \multirow{5}{*}{$47.681^{\star \star \star}$} & \multirow{5}{*}{0.280} \\
\hline & Lower Middle & 32.3148 & 9.13619 & 108 & & \\
\hline & Middle & 35.2420 & 8.06983 & 159 & & \\
\hline & Upper Middle & 41.0096 & 7.77585 & 119 & & \\
\hline & High & 44.7307 & 7.27783 & 41 & & \\
\hline \multirow{5}{*}{$\begin{array}{l}\text { Mathematics as a social } \\
\text { activity }\end{array}$} & Low & 22.1159 & 5.24835 & 69 & \multirow{5}{*}{$13.425^{\star \star \star}$} & \multirow{5}{*}{0.099} \\
\hline & Lower Middle & 23.7037 & 6.32346 & 108 & & \\
\hline & Middle & 24.7107 & 5.22330 & 159 & & \\
\hline & Upper Middle & 27.1933 & 5.01401 & 119 & & \\
\hline & High & 27.6098 & 5.87741 & 41 & & \\
\hline \multirow{5}{*}{ Mathematics anxiety } & Low & 13.8406 & 5.59049 & 69 & \multirow{5}{*}{2.212 n.s. } & \multirow{5}{*}{0.018} \\
\hline & Lower Middle & 14.3426 & 4.61238 & 108 & & \\
\hline & Middle & 14.8868 & 3.88111 & 159 & & \\
\hline & Upper Middle & 15.2941 & 4.75564 & 119 & & \\
\hline & High & 16.1707 & 5.62095 & 41 & & \\
\hline
\end{tabular}

Note: ${ }^{* \star \star} p<.001$, n.s. $p>.05$

Perceived Achievement 
more desirable mathematics-related beliefs. This supports the finding of Levpušček and Zupančič (2009) regarding the importance for mathematics achievement of the support and encouragement that mathematics teachers can offer to students. It is notable, however, that in this Chinese sample, only a relatively small percentage (about 28\%) of students reported that their teachers gave them praise. This is a surprisingly small percentage that leaves room to explore how increasing teacher praise might influence students' mathematical beliefs and achievement.

Second, students' reported mathematics achievement level in their classes was positively related to teacher praise. This is consistent with the findings of some studies (e.g., Phillipson, 2010; Rodríguez et al., 2017). The uniqueness of this study is that students' perceived mathematics achievement rank is quite consistent with the data.

Finally, math anxiety is something of an outlier among the four mathematics-related beliefs subscales in the sense that the relationship between this subscale is not correlated in the same way as the other subscales with the other variables. This finding could be interpreted as reflecting the possibility that a certain degree of math anxiety is a good thing for math learning. However, too low or too high a degree of math anxiety may not be healthy for students' math learning. Prior research on math anxiety has revealed that the relationships between math anxiety and achievement are exceedingly complex (Ma, 1999). Based on our findings in this study, we might hypothesize that neither too little anxiety nor too much anxiety produces a strong correlation with achievement. This suggests that a future direction for exploration would be to understand how much math anxiety is beneficial for supporting desirable math beliefs and achievement.

The findings of this study have implications for pedagogical practice. In order to help students develop desirable mathematics-related beliefs, teachers may be able to strategically use praise. In this study, over $70 \%$ of the students viewed that their teacher did not give them praise. This implies that there is quite a bit of room to increase praise to encourage more desirable beliefs. This study confirms the positive effects of mathematics teachers' praise on students' mathematics-related beliefs and achievement. This suggests that good communication between mathematics teachers and students could greatly benefit students' mathematics-related beliefs. However, blindly pursuing the delivery of children to prestigious classes in an effort to pressure them to academically perform in mathematics may result in comparatively poor mathematics grades, resulting in less desirable mathematics-related beliefs and further affecting students' mathematics self-efficacy and performance.

A limitation of this study is that it is based purely on survey data collected from students. Thus, information on teachers' praise is channeled entirely through the reporting of the students. A future study is needed to go beyond examining only students' perceptions about teachers' praise to also collect data directly from teachers, as well as to collect actual student mathematics achievement data.

\section{Endnote}

1. A series of multiple linear regression analyses were also explored for these data, with the total belief score and each subscale score as the dependent variable and the teacher praise as predictor. Given the categorial/ordinal nature of the teacher praise variable, these analyses did not illuminate the data beyond the ANOVA analyses (neither did they contradict the ANOVA findings). Thus, those results are not reported here.

\section{REFERENCES}

Anderson, J. C., \& Gerbing, D. W. (1984). The effect of sampling error on convergence, improper solutions, and goodness-of-fit indices for maximum likelihood confirmatory factor analysis. Psychometrika, 49(2), 155-173. https://doi.org/10.1007/BF02294170

Cai, J. (1995). A cognitive analysis of US and Chinese students' mathematical performance on tasks involving computation, simple problem solving, and complex problem solving. Journal for Research in Mathematics Education Monographs Series No. 7, Reston, VA: National Council of Teachers of Mathematics.

Cai, J. \& Merlino, F. J. (2011). Metaphor: A powerful means for assessing students' mathematical disposition. In D. J. Brahier \& W. Speer (Eds.), Motivation and disposition: Pathways to learning mathematics (pp.147-156). National Council of Teachers of Mathematics 2011 Yearbook. Reston, VA: NCTM.

Cai, J., Morris, A., Hohensee, C., Hwang, S., Robison, V., \& Hiebert, J. (2017). Clarifying the impact of educational research on students' learning. Journal for Research in Mathematics Education, 48(2), 118-123. https://doi.org/10.5951/jresematheduc.48.2.0118

Clarkson, P. C., Bishop, A., \& Seah, W. T. (2010). Mathematics education and student values: The cultivation of mathematical wellbeing. In T. Lovat, R. Toomey, \& N. Clement (Eds.), International research handbook on values education and student wellbeing (pp. 111-136). Dordrecht: Springer. https:/ / doi.org/10.1007/978-90-481-86754_7 
Fan, L., Wong, N-Y., Cai, J. \& Li, S. (Eds.). (2004). How Chinese learn mathematics: Perspectives from insiders. Singapore: World Scientific Publishers. https:/ / doi.org/10.1142/5629

Fennema, E., \& Sherman, J. A. (1976). Fennema-Sherman mathematics attitudes scales: instruments designed to measure attitudes toward the learning of mathematics by females and males. Journal for Research in Mathematics Education, 7(5), 324-326. https:/ / doi.org/10.2307/748467

Goodenow, C. (1993). Classroom belonging among early adolescent students: Relationships to motivation and achievement. The Journal of Early Adolescence, 13(1), 21-43. https:/ / doi.org/10.1177/0272431693013001002

Hannula, M. S., Bofah, E., Tuohilampi, L., \& Metsämuuronen, J. (2014). A longitudinal analysis of the relationship between mathematics-related affect and achievement in Finland. In S. Oesterle, P. Liljedahl, C. Nicol \& D. Allan (Eds.), Proceedings of the 38th conference of the IGPME and the 36th conference of the PME-NA (Vol. 3, pp. 249-256). Vancouver, Canada: PME.

House, J. D. (2009). Mathematics beliefs and achievement of a national sample of native american students: results from the trends in international mathematics and science study (timss) 2003 united states assessment. Psychological Reports, 104(2), 439. https:/ / doi.org/10.2466/PR0.104.2.439-446

Lapointe, J. M., Legault, F., \& Batiste, S. J. (2005). Teacher interpersonal behavior and adolescents' motivation in mathematics: a comparison of learning disabled, average, and talented students. International Journal of Educational Research, 43(1), 39-54. https:/ / doi.org/10.1016/j.ijer.2006.03.005

Lay, Y. F., Ng, K. T., \& Chong, P. S. (2015). Analyzing affective factors related to eighth grade learners' science and mathematics achievement in TIMSS 2007. The Asia-Pacific Education Researcher, 24(1), 103-110. https:/ / doi.org/10.1007/s40299-013-0163-0

Leder, G. C. (1993). Teacher/student interactions in the mathematics classroom: A different perspective. In E. Fennema \& G. C. Leder (Eds.), Mathematics and gender (149-168). Queensland, Australia: Queensland University Press.

Levpušček, M. P., \& Zupančič, M. (2009). Math achievement in early adolescence: the role of parental involvement, teachers' behavior, and students' motivational beliefs about math. Journal of Early Adolescence, 29(4), 541-570. https:/ / doi.org/10.1177/0272431608324189

Ma, X. (1999). A meta-analysis of the relationship between anxiety toward mathematics and achievement in mathematics. Journal for Research in Mathematics Education, 30(5), 520-540. https: / / doi.org/10.2307/749772

Marchant, G. J., Paulson, S. E., \& Rothlisberg, B. A. (2001). Relations of middle school students' perceptions of family and school contexts with academic achievement. Psychology in the Schools, 38(6), 505-519. https:/ / doi.org/10.1002/ pits.1039

McLeod, D. B. (1992). Research on affect in mathematics education: A reconceptualization. In D. Grouws (Ed.), Handbook of research on mathematics teaching and learning: A project of the National Council of Teachers of Mathematics (pp. 575-596). New York, NY: Macmillan.

Middleton, J., Jansen, A., \& Goldin, G. A. (2017). The complexities of mathematical engagement: Motivation, affect, and social interactions. In J. Cai (Ed.), Compendium for research in mathematics education (pp. 667-699). Reston, VA: National Council of Teachers of Mathematics.

Moyer J. C., Robison, V., \& Cai, J. (2018). Attitudes of high-school students taught using traditional and reform mathematics curricula in middle school: A retrospective analysis. Educational Studies in Mathematics, 98(2), 115-134. https:/ / doi.org/10.1007/s10649-018-9809-4

Op't Eynde, P., \& De Corte, E. (2003). Students' mathematics-related belief systems: Design and analysis of a questionnaire. Paper presented at the meeting of the American Educational Research Association, Chicago, IL.

Op't Eynde, P., De Corte, E., \& Verschaffel, L. (2002). Framing students' mathematics-related beliefs. In Leder, G. C., Pehkonen, E., \& Törner, G. (Eds.), Beliefs: A hidden variable in mathematics education? (pp. 13-37). Dordrecht: Springer. https://doi.org/10.1007/0-306-47958-3_2

Pantziara, M. (2016). Student self-efficacy beliefs. In G. A. Goldin, M. S. Hannula, E. Heyd-Metzuyanim, A. Jansen, R. Kaasila, S. Lutovac, ... Q. Zhang (Eds.), Attitudes, beliefs, motivation and identity in mathematics education: An overview of the field and future directions (pp. 7-11). Dordrecht: Springer.

Patrick, H., Ryan, A. M., \& Kaplan, A. (2007). Early adolescents' perceptions of the classroom social environment, motivational beliefs, and engagement. Journal of Educational Psychology, 99(1), 83-98. https:/ / doi.org/10.1037/0022-0663.99.1.83

Pepin, B., \& Roesken-Winter, B. (Eds.). (2015). From beliefs to dynamic affect systems in mathematics education: Exploring a mosaic of relationships and interactions. Dordrecht: Springer. https:/ / doi.org/10.1007/978-3-319-06808-4

Phillipson, S. (2010). Parental role in relation to students' cognitive ability towards academic achievement in Hong Kong. The Asia-Pacific Education Researcher, 19(2). https:/ / doi.org/10.3860/taper.v19i2.1594 
Phillipson, S., \& Phillipson, S. N. (2007). Academic expectations, belief of ability, and involvement by parents as predictors of child achievement: A cross-cultural comparison. Educational Psychology, 27(3), 329-348. https:/ / doi.org/10.1080/01443410601104130

Rodríguez, S., Piñeiro, I., Gómez-Taibo, M. L., Regueiro, B., Estévez, I., \& Valle, A. (2017). An explanatory model of maths achievement:perceived parental involvement and academic motivation. Psicothema, 29(2), 184.

Schneider, B., \& Lee, Y. A model for academic success: The school and home environment of East Asian students. Anthropology \& Education Quarterly, 21(4), 358-377. https:/ / doi.org/10.1525/aeq.1990.21.4.04x0596x

Schoenfeld, A. H. (1989). Explorations of students' mathematical beliefs and behavior. Journal for Research in Mathematics Education, 20(4), 338-355. https:/ / doi.org/10.2307/749440

Schoenfeld, A. H. (1992). Learning to think mathematically: Problem solving, metacognition, and sense making in mathematics. In D. A. Grouws (Ed.), Handbook of research on mathematics teaching and learning: A project of the National Council of Teachers of Mathematics (pp. 334-370). New York, NY, England: Macmillan Publishing Co, Inc.

Skaalvik, E. M., \& Skaalvik, S. (2011). Self-concept and self-efficacy in mathematics: Relation with mathematics motivation and achievement. Journal of Education Research, 5(3/4), 241-265.

Wentzel, K. R. (1997). Student motivation in middle school: The role of perceived pedagogical caring. Journal of Educational Psychology, 89(3), 411-419. https:/ / doi.org/10.1037/0022-0663.89.3.411

Zijlstra, H., Wubbels, T., Brekelmans, M., \& Koomen, H. M. Y. (2013). Child perceptions of teacher interpersonal behavior and associations with mathematics achievement in dutch early grade classrooms. Elementary School Journal, 113(4), 517-540. https:/ / doi.org/10.1086/669618

\section{APPENDIX}

\section{High School Student Mathematics Belief Questionnaire}

The questionnaire items listed below are grouped by subscale. The items' positions in the questionnaire as administered were randomized.

\section{Subscale 1: Beliefs About the Role and Functioning of Their Own Teacher}

I am interested in what my teacher says in mathematics lessons

My mathematics teacher is easy to understand

The mathematics teacher asks me or my classmates to specify our thinking or reasoning

The mathematics teacher asks questions to check whether we have understood what was taught

The mathematics teacher gives students an opportunity to express opinions

The mathematics teacher sets clear goals for our learning

The teacher tells me what I need to do to become better in mathematics

My mathematics teacher has clear answers to my questions

At the beginning of a mathematics lesson, the teacher presents a short summary of the previous lesson

Our mathematics teacher listens carefully when we ask or say something

Our teacher explains why mathematics is important

Our mathematics teacher appreciates it when we have tried hard, even if our results are not so good

Our mathematics teacher gives us time to really explore new problems and to try out possible solution strategies

\section{Subscale 2: Beliefs about the significance of and competence in mathematics}

I can understand even the most difficult material presented in a mathematics course

Mathematics is one of my favorite subjects

If I wanted to I could do better in mathematics

I am good at working out difficult mathematics problems

I enjoy learning mathematics 
I learn high school mathematics quickly

I'm very interested in mathematics

I look forward to my mathematics lessons

It is important to learn mathematics

I need mathematics to learn other school subjects such as physics, geography, etc.

I like doing mathematics

\section{Subscale 3: Mathematics as a social activity}

Mathematics is benefit for human development

Mathematics is used by a lot of people in their daily life

Development of many disciplines depends on mathematics

I learn many interesting things in mathematics

I think I will be able to use what I learn in mathematics also in other courses

Mathematics enables men to better understand the world he lives in

I am willing to pursue a major in mathematics at university

\section{Subscale 4: Mathematics anxiety}

Mathematics is harder for me than any other subject

Mathematics is more difficult for me than for many of my classmates

I have no confidence in myself before learning new mathematics

High school mathematics makes me anxious

Mathematics is not one of my strengths

\section{http://www.ejmste.com}

